\title{
Design and Optimization of the Direct Recycling of Spent Li-ion Battery Cathode Materials
}

Panpan Xu, ${ }^{1}$ Zhenzhen Yang, ${ }^{2}$ Xiaolu Yu, ${ }^{3}$ John Holoubek, ${ }^{1}$ Hongpeng Gao, ${ }^{3}$ Mingqian Li, ${ }^{1}$ Guorui Cai, ${ }^{1}$ Ira Bloom,${ }^{2}$ Haodong Liu, ${ }^{1}$ Yan Chen, ${ }^{4}$ Ke An, ${ }^{4}$ Krzysztof Z. Pupek, ${ }^{5}$ Ping Liu, $, 3,6,7$ Zheng Chen ${ }^{1,3,6,7 *}$

${ }^{1}$ Department of NanoEngineering, University of California, San Diego, 9500 Giman Drive, La Jolla, CA 92093, USA

${ }^{2}$ Chemical Sciences and Engineering Division, Argonne National Laboratory, 9700 South Cass Avenue, Lemont, IL 60439, USA

${ }^{3}$ Program of Materials Science, University of California, San Diego, 9500 Giman Drive, La Jolla, CA 92093, USA

${ }^{4}$ Neutron Scattering Division, Oak Ridge National Laboratory, 1 Bethel Valley Rd, Oak Ridge, TN, 37830, USA

${ }^{5}$ Applied Materials Division, Argonne National Laboratory, 9700 South Cass Avenue, Lemont, IL 60439, USA

${ }^{6}$ Sustainable Power and Energy Center, University of California, San Diego, 9500 Giman Drive, La Jolla, CA 92093 , USA

${ }^{7}$ Program of Chemical Engineering, University of California, San Diego, 9500 Giman Drive, La Jolla, CA 92093, USA

Corresponding to zhengchen@eng.ucsd.edu (Z. C.)

Number of pages: 23

Number of figures: 15

Number of tables: 6 

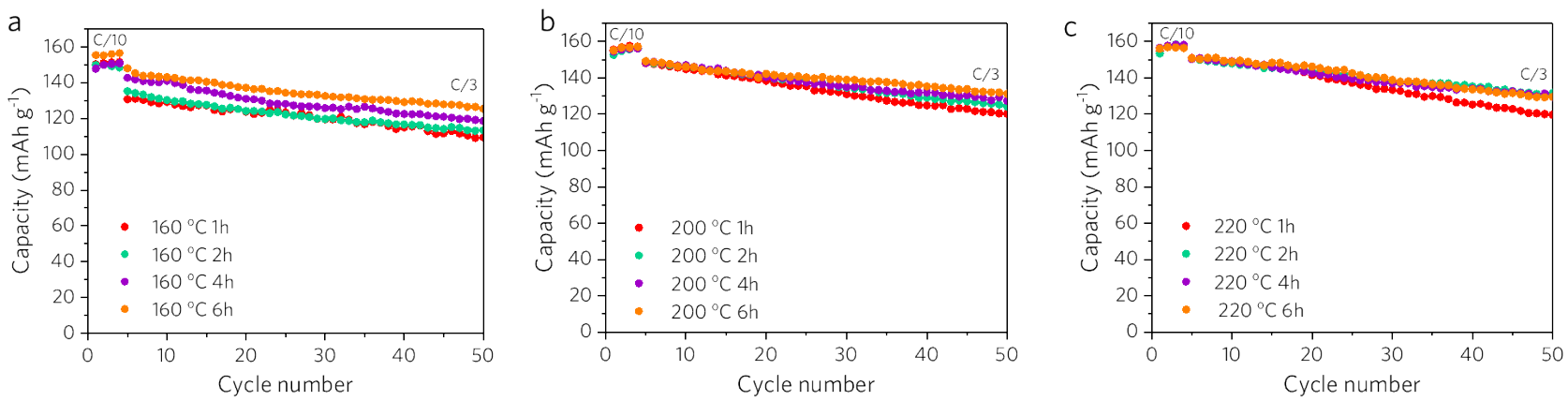

Figure S1. Cycling stability of hydrothermally relithiated NCM111 at $160{ }^{\circ} \mathrm{C}(\mathbf{a}), 200{ }^{\circ} \mathrm{C}$ (b) and 220 ${ }^{\circ} \mathrm{C}$ (c) for different durations ranging from $1 \mathrm{~h}, 2 \mathrm{~h}, 4 \mathrm{~h}$ and $6 \mathrm{~h}$. 
Table S1. Capacity retention of relithiated NCM111 at the C/3 rate.

\begin{tabular}{|c|c|c|c|}
\hline \multirow{2}{*}{ Samples } & \multicolumn{2}{|c|}{ Discharge capacity $(\mathrm{mAh} / \mathrm{g})$} & \multirow{2}{*}{ Retention $(\%)$} \\
\hline & $1^{\text {st }}$ cycle & $50^{\text {th }}$ cycle & \\
\hline $\mathrm{HT}-160{ }^{\circ} \mathrm{C}-1 \mathrm{~h}$ & 130 & 106 & $81.5 \%$ \\
\hline HT- $160^{\circ} \mathrm{C}-2 \mathrm{~h}$ & 135 & 113 & $83.7 \%$ \\
\hline HT- $160{ }^{\circ} \mathrm{C}-4 \mathrm{~h}$ & 142 & 119 & $83.8 \%$ \\
\hline HT- $160{ }^{\circ} \mathrm{C}-6 \mathrm{~h}$ & 147 & 125 & $85.0 \%$ \\
\hline HT-200 ${ }^{\circ} \mathrm{C}-1 \mathrm{~h}$ & 147 & 120 & $81.6 \%$ \\
\hline HT-200 ${ }^{\circ} \mathrm{C}-2 \mathrm{~h}$ & 148 & 124 & $83.7 \%$ \\
\hline HT-200 ${ }^{\circ} \mathrm{C}-4 \mathrm{~h}$ & 148 & 127 & $85.8 \%$ \\
\hline HT-200 ${ }^{\circ} \mathrm{C}-6 \mathrm{~h}$ & 149 & 130 & $87.2 \%$ \\
\hline HT-220 ${ }^{\circ} \mathrm{C}-1 \mathrm{~h}$ & 149 & 120 & $80.5 \%$ \\
\hline HT- $220^{\circ} \mathrm{C}-2 \mathrm{~h}$ & 150 & 131 & $87.3 \%$ \\
\hline HT- $220^{\circ} \mathrm{C}-4 \mathrm{~h}$ & 150 & 130 & $86.7 \%$ \\
\hline HT-220 ${ }^{\circ} \mathrm{C}-6 \mathrm{~h}$ & 151 & 130 & $86.1 \%$ \\
\hline
\end{tabular}


Table S2. Values of the fitting parameters.

\begin{tabular}{ll}
\hline Parameter & Value (s.e.e) \\
\hline$a_{1}$ & $0.73(0.02)$ \\
$a_{2}$ & $26.29(3.71)$ \\
$b_{2}$ & $-0.13(0.02)$ \\
\hline
\end{tabular}

* standard error of the estimate 




Figure S2. XRD patterns of samples relithiated at temperatures of $160^{\circ} \mathrm{C}, 200^{\circ} \mathrm{C}$ and $220^{\circ} \mathrm{C}$, as well as control samples (T-NCM111 and D-NCM111), respectively. 


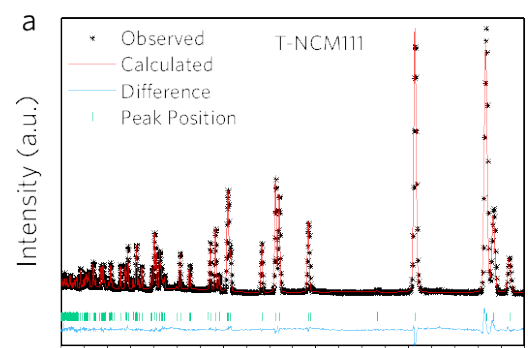

$\begin{array}{llllllllll}0.6 & 0.8 & 1.0 & 1.2 & 1.4 & 1.6 & 1.8 & 2.0 & 2.2 & 2.4\end{array}$ d-spacing $(\AA)$

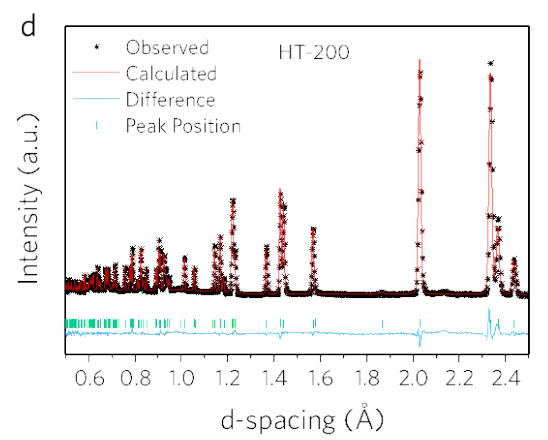

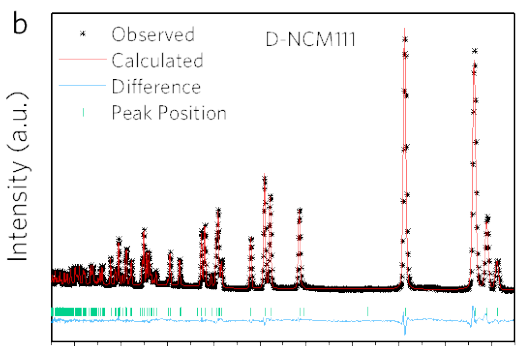

$\begin{array}{llllllllll}0.6 & 0.8 & 1.0 & 1.2 & 1.4 & 1.6 & 1.8 & 2.0 & 2.2 & 2.4\end{array}$ d-spacing $(\AA)$

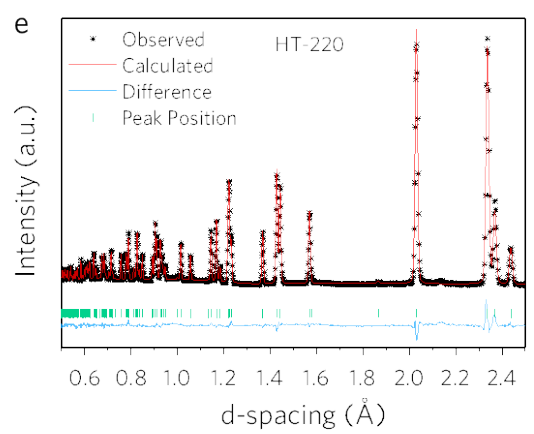

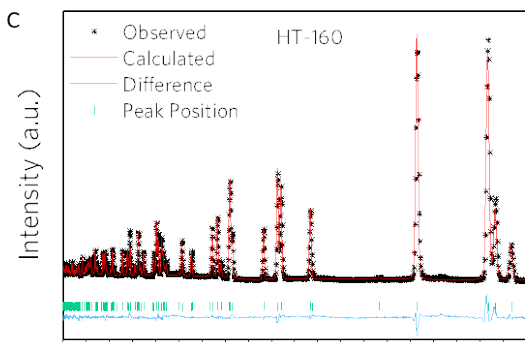

$\begin{array}{llllllllll}0.6 & 0.8 & 1.0 & 1.2 & 1.4 & 1.6 & 1.8 & 2.0 & 2.2 & 2.4\end{array}$ d-spacing $(\AA)$

Figure S3. Neutron diffraction patterns of relithiated T-NCM111 (a), d-NCM111 (b), NCM111 at 160 ${ }^{\circ} \mathrm{C}(\mathbf{c}), 200{ }^{\circ} \mathrm{C}$ (d) and $220{ }^{\circ} \mathrm{C}$ (e) by Rietveld refinement. The black dots, red line, blue line, and green vertical tick marks represent the observed, calculated, difference pattern, and peak position, respectively. 




Figure S4. CV curves D-NCM111 tested in aqueous electrolytes of 4M KOH and 4M LiOH with $\mathrm{Ag} / \mathrm{AgCl}$ as the reference electrode. 

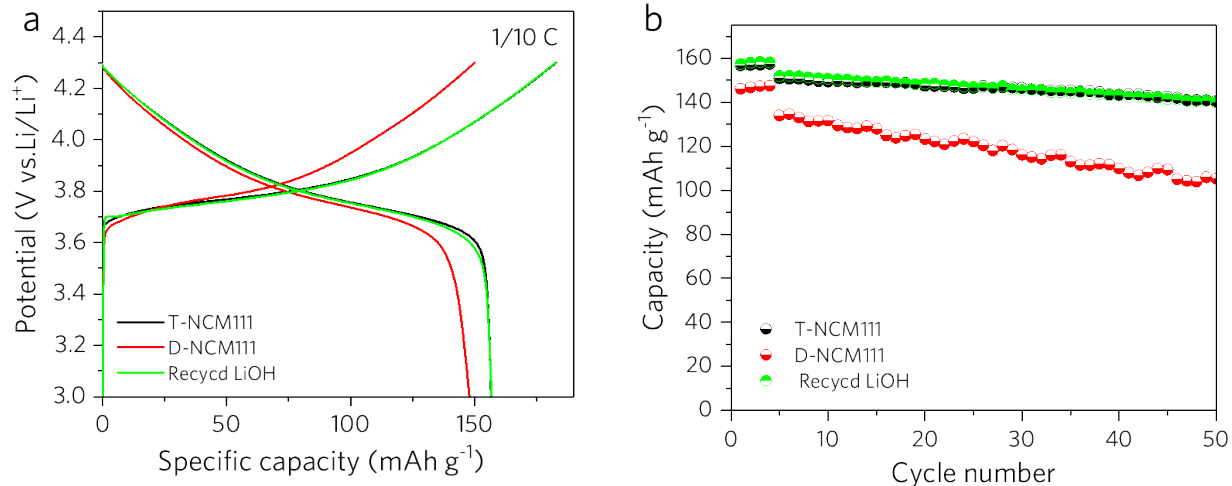

Figure S5. Voltage profiles (a) and cycling stability (b) of the sample regenerated with recycled LiOH and the control samples (T-NCM111 and D-NCM111). 

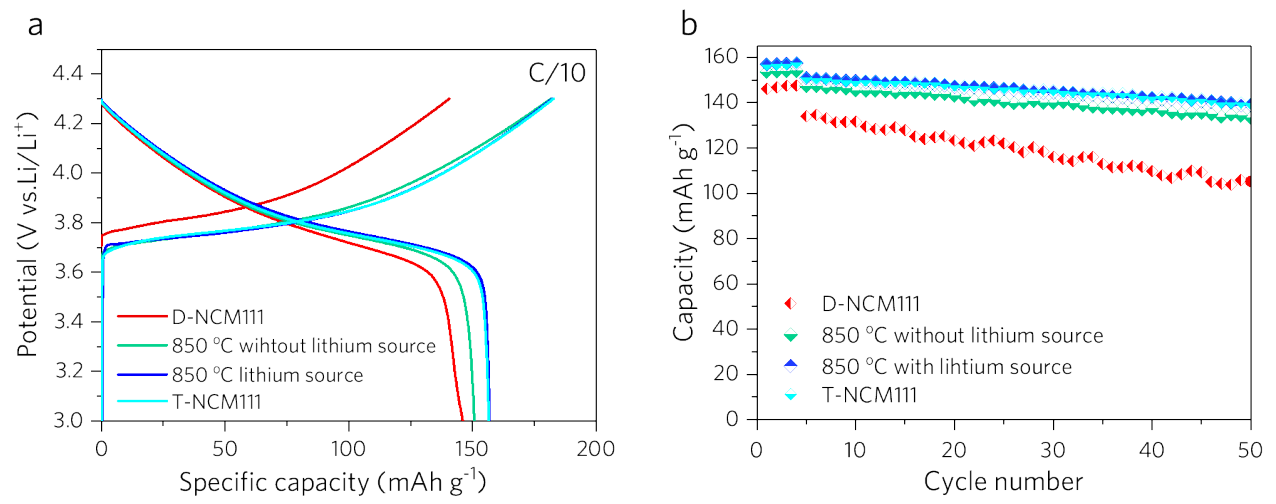

Figure S6. Voltage profiles (a) and cycling stability (b) of the relithiated sample annealed at $850{ }^{\circ} \mathrm{C}$ with and without lithium source and the control samples (T-NCM111 and D-NCM111). 


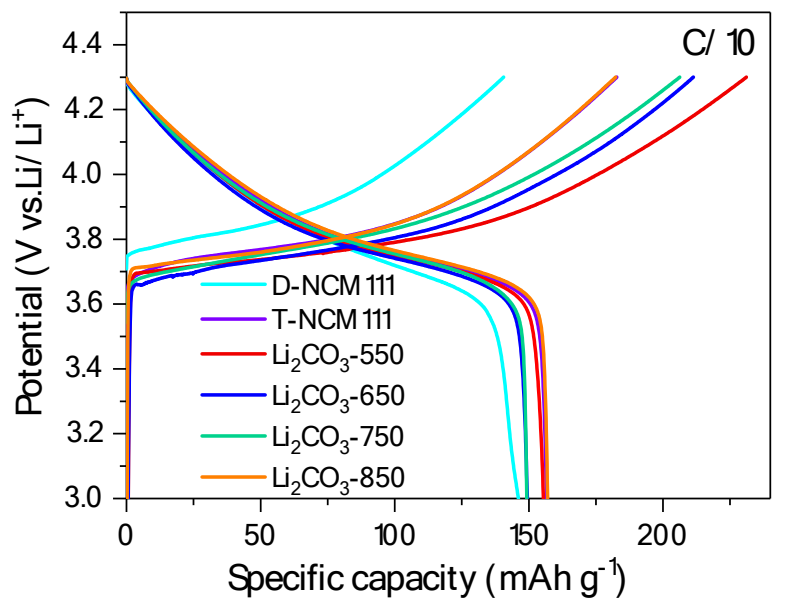

Figure S7. Voltage profiles the relithiated sample annealed with $\mathrm{Li}_{2} \mathrm{CO}_{3}$ at temperatures of $550{ }^{\circ} \mathrm{C}$, $650{ }^{\circ} \mathrm{C}, 750{ }^{\circ} \mathrm{C}$ and $850{ }^{\circ} \mathrm{C}$. 


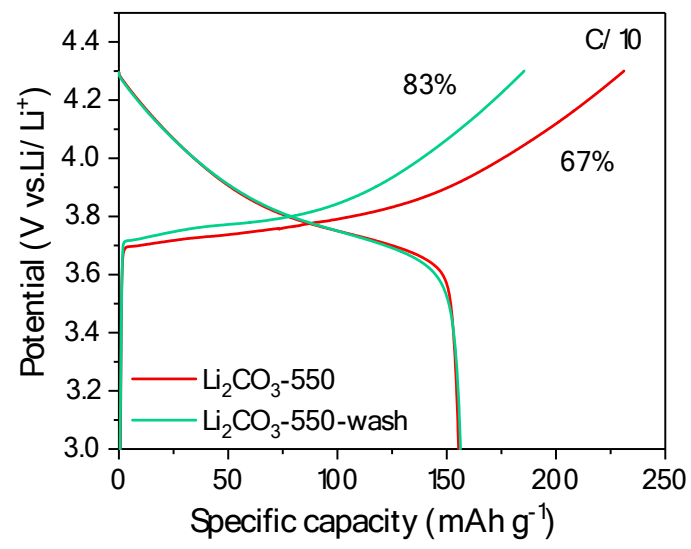

Figure S8. Voltage profiles the relithiated sample annealed with $\mathrm{Li}_{2} \mathrm{CO}_{3}$ at $550{ }^{\circ} \mathrm{C}$ before and after washing. 




Figure S9. Cycling stability of relithiated samples annealed with $\mathrm{Li}_{2} \mathrm{CO}_{3}$ at $850{ }^{\circ} \mathrm{C}$ for $1 \mathrm{~h}, 2 \mathrm{~h}, 4 \mathrm{~h}$, and $6 \mathrm{~h}$. 


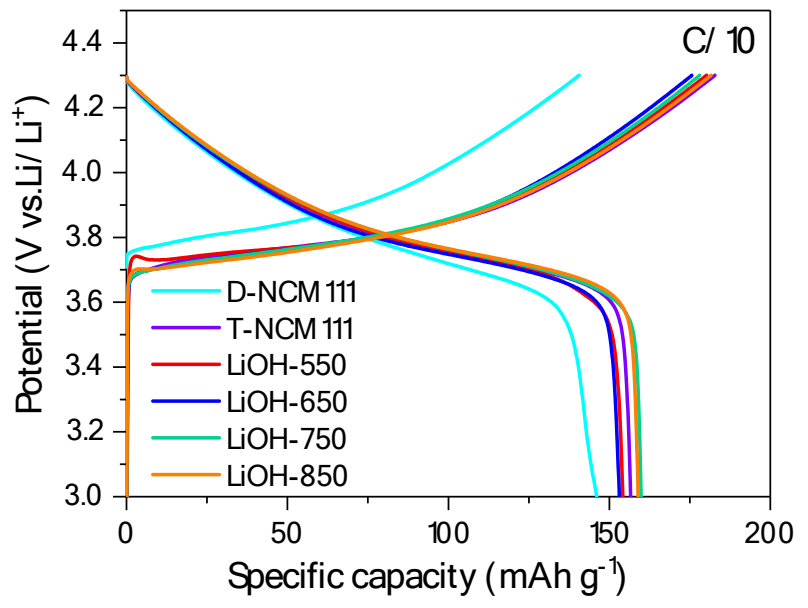

Figure S10. Voltage profiles of the relithiated sample annealed with $\mathrm{LiOH}$ at temperatures of $550{ }^{\circ} \mathrm{C}$, $650^{\circ} \mathrm{C}, 750{ }^{\circ} \mathrm{C}$ and $850^{\circ} \mathrm{C}$. 
Table S3. Capacity retention (C/3 rate) of relithiated $\mathrm{NCM} 111$ after annealing with $\mathrm{Li}_{2} \mathrm{CO}_{3}$ and LiOH.

\begin{tabular}{|c|c|c|c|}
\hline \multirow{2}{*}{ Samples } & \multicolumn{2}{|c|}{ Discharge capacity $(\mathrm{mAh} / \mathrm{g})$} & \multirow{2}{*}{ Retention $(\%)$} \\
\hline & $1^{\text {st }}$ cycle & $50^{\text {th }}$ cycle & \\
\hline $\mathrm{HT}-\mathrm{Li}_{2} \mathrm{CO}_{3}-550^{\circ} \mathrm{C}$ & 145.3 & 127.4 & $87.7 \%$ \\
\hline $\mathrm{HT}-\mathrm{Li}_{2} \mathrm{CO}_{3}-650^{\circ} \mathrm{C}$ & 146.4 & 129.4 & $88.4 \%$ \\
\hline $\mathrm{HT}-\mathrm{Li}_{2} \mathrm{CO}_{3}-750{ }^{\circ} \mathrm{C}$ & 148.6 & 134.4 & $90.4 \%$ \\
\hline $\mathrm{HT}-\mathrm{Li}_{2} \mathrm{CO}_{3}-850^{\circ} \mathrm{C}$ & 150.6 & 140.3 & $93.2 \%$ \\
\hline HT-LiOH-550 ${ }^{\circ} \mathrm{C}$ & 145.4 & 124.6 & $85.7 \%$ \\
\hline HT-LiOH- $650{ }^{\circ} \mathrm{C}$ & 148.2 & 128.3 & $86.5 \%$ \\
\hline $\mathrm{HT}-\mathrm{LiOH}-750^{\circ} \mathrm{C}$ & 150.5 & 140.4 & $93.3 \%$ \\
\hline $\mathrm{HT}-\mathrm{LiOH}-850^{\circ} \mathrm{C}$ & 150.6 & 140.6 & $93.4 \%$ \\
\hline D-NCM111 & 133.9 & 105.3 & $78.6 \%$ \\
\hline T-NCM111 & 150.8 & 140.5 & $93.2 \%$ \\
\hline
\end{tabular}



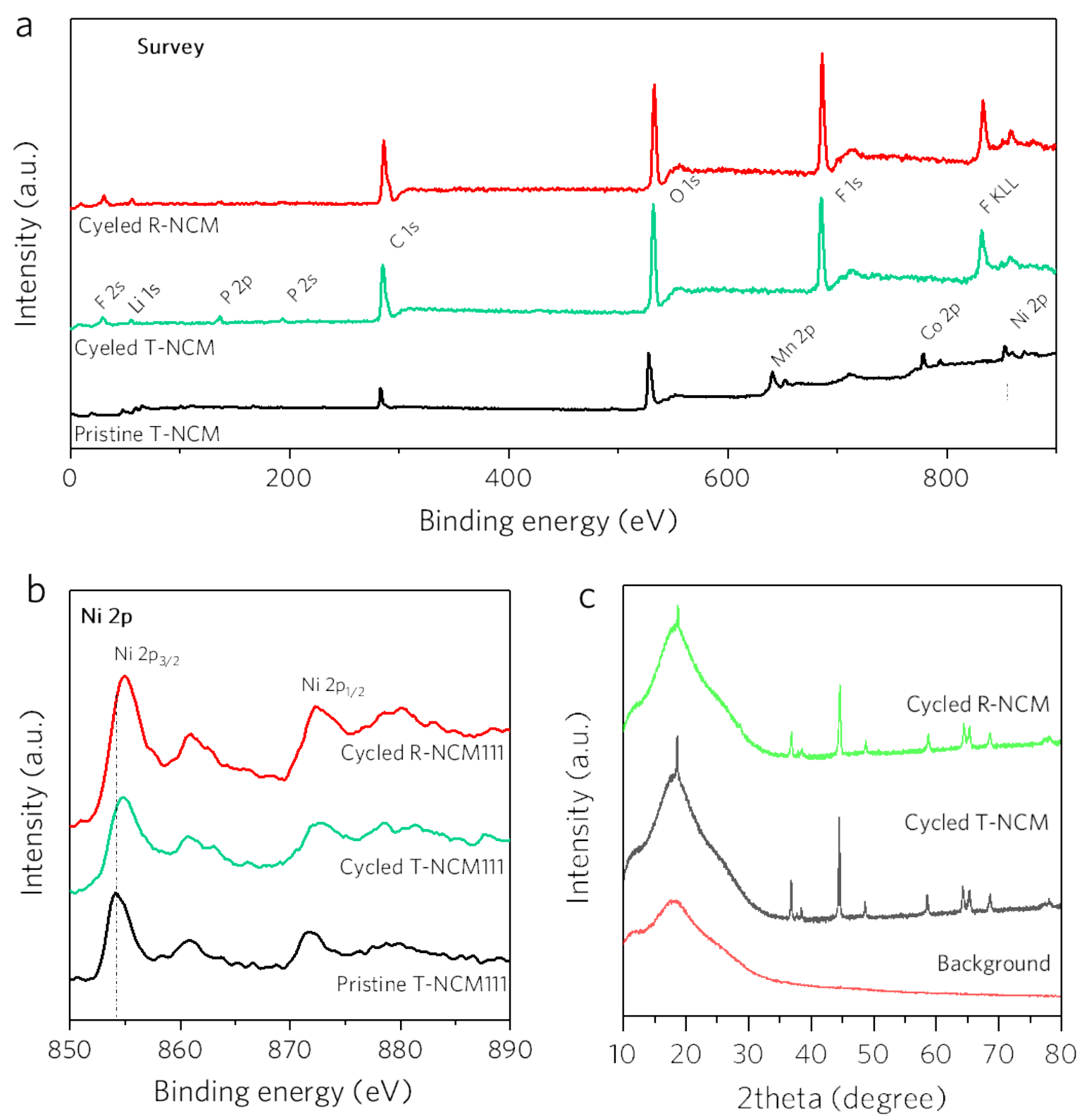

Figure S11. XPS survey spectra (a) and high-resolution XPS spectra of Ni 2p (b), as well as the XRD patterns (c) of cycled T-NCM R-NCM. 
Table S4. The composition of NCM111 regenerated at different scales and the control samples (DNCM111 and T-NCM111).

\begin{tabular}{cc}
\hline Sample & Composition \\
\hline D-NCM111 & $\mathrm{Li}_{0.9} \mathrm{Ni}_{0.33} \mathrm{Co}_{0.33} \mathrm{Mn}_{0.33} \mathrm{O}_{2}$ \\
R-NCM111-1g & $\mathrm{Li}_{1.05} \mathrm{Ni}_{0.33} \mathrm{Co}_{0.33} \mathrm{Mn}_{0.33} \mathrm{O}_{2}$ \\
R-NCM111-10g & $\mathrm{Li}_{1.07} \mathrm{Ni}_{0.33} \mathrm{Co}_{0.33} \mathrm{Mn}_{0.33} \mathrm{O}_{2}$ \\
T-NCM111 & $\mathrm{Li}_{1.06} \mathrm{Ni}_{0.33} \mathrm{Co}_{0.33} \mathrm{Mn}_{0.33} \mathrm{O}_{2}$ \\
\hline
\end{tabular}



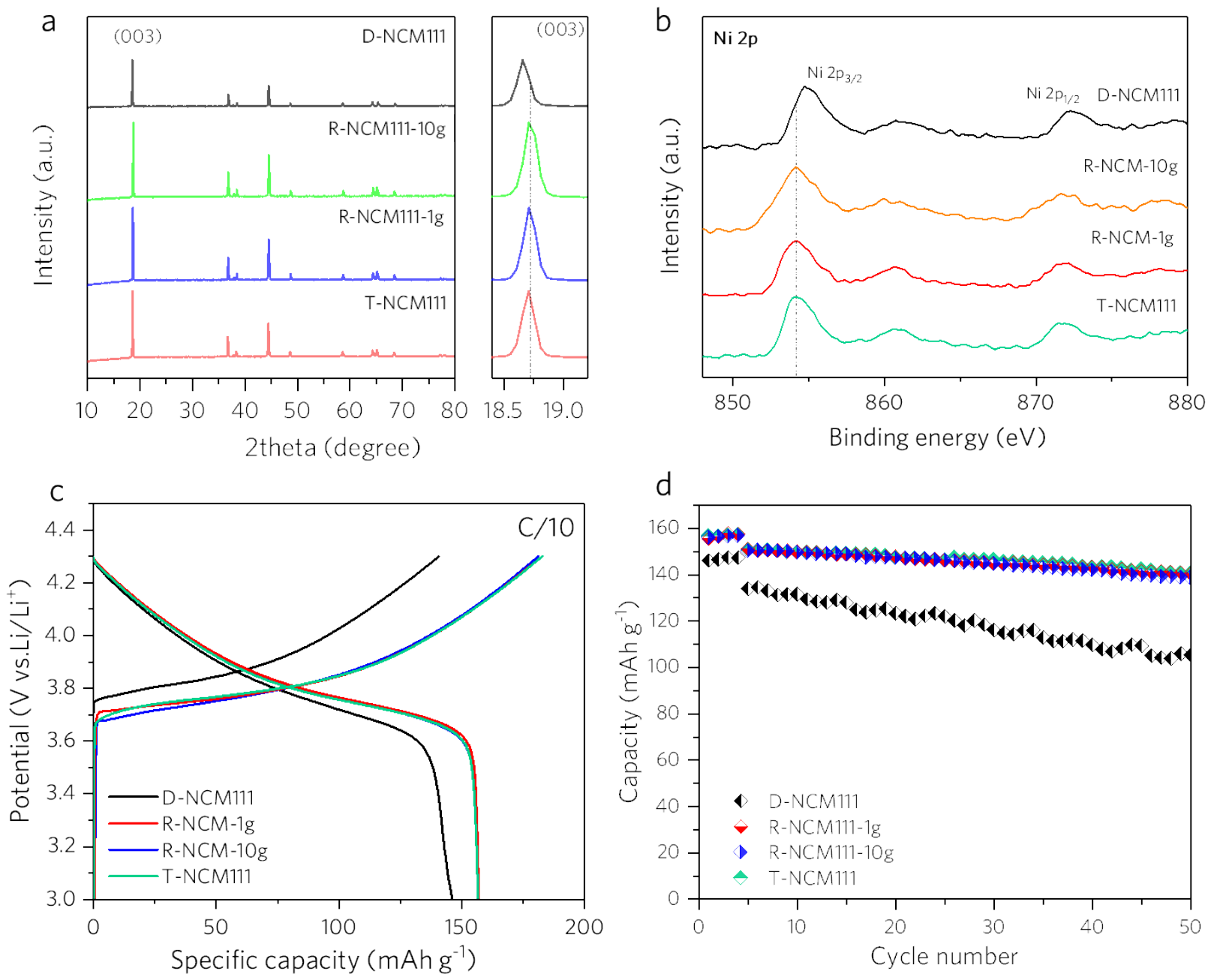

Figure S12. XRD patterns (a), Ni 2p XPS spectra (b), voltage curves (c), and cycling stability of NCM111 cathodes regenerated at $1 \mathrm{~g}$ and $10 \mathrm{~g}$ scales, as well as the control samples (D-NCM111 and T-NCM111) (d). 


\section{Economic and environmental analysis}

The EverBatt model, a closed-loop battery recycling model developed at Argonne National Laboratory, ${ }^{1}$ was used to conduct a techno-economic and life-cycle analysis of pyrometallurgical, hydrometallurgical, and direct cathode recycling processes.

In the pyrometallurgical recycling process (Figure S13), spent LIBs are sent to a smelter, where electrolyte and plastics in the batteries are burned to supply heat; graphite/carbon and aluminum in the batteries act as reductants for the metals and are oxidized; cobalt, nickel, copper, and iron in the batteries end up in the matte; and the rest of the materials, including oxidized aluminum end up in the slag. The $\mathrm{Co} / \mathrm{Ni} / \mathrm{Cu} / \mathrm{Fe}$ matte is then further processed by acid leaching followed by solvent extraction and precipitation to produce cobalt and nickel compounds that can be used for new cathode materials production.

In the pyrometallurgical recycling process (Figure S14), discharged and dissembled spent batteries are shredded, and then undergo a low-temperature calcination process to burn the binder and electrolyte; several physical separation processes to separate out aluminum, copper, steel as metal scraps and plastics; and a leaching process followed by solvent extraction and sometimes precipitation to produce $\mathrm{Co} / \mathrm{Ni} / \mathrm{Mn}$ compounds and potentially lithium carbonate for new cathode material production.

The generic direct recycling process in EverBatt was modified in this study to reflect the changes in the process design, as depicted in Figure S15. In the direct recycling process, batteries are discharged, dissembled, and shredded. After that, the materials undergo a series of physical separation processes to separate out scrap metals, plastics, anode powder and cathode powder. After separation, the harvested cathode materials are sent to relithiation and thermal annealing to produce rejuvenated cathode powder.

The three recycling plants, featuring pyrometallurgical, hydrometallurgical, and direct recycling processes, respectively, are assumed to be based on processing 10,000 metric tons of battery cells per year in the U.S. 


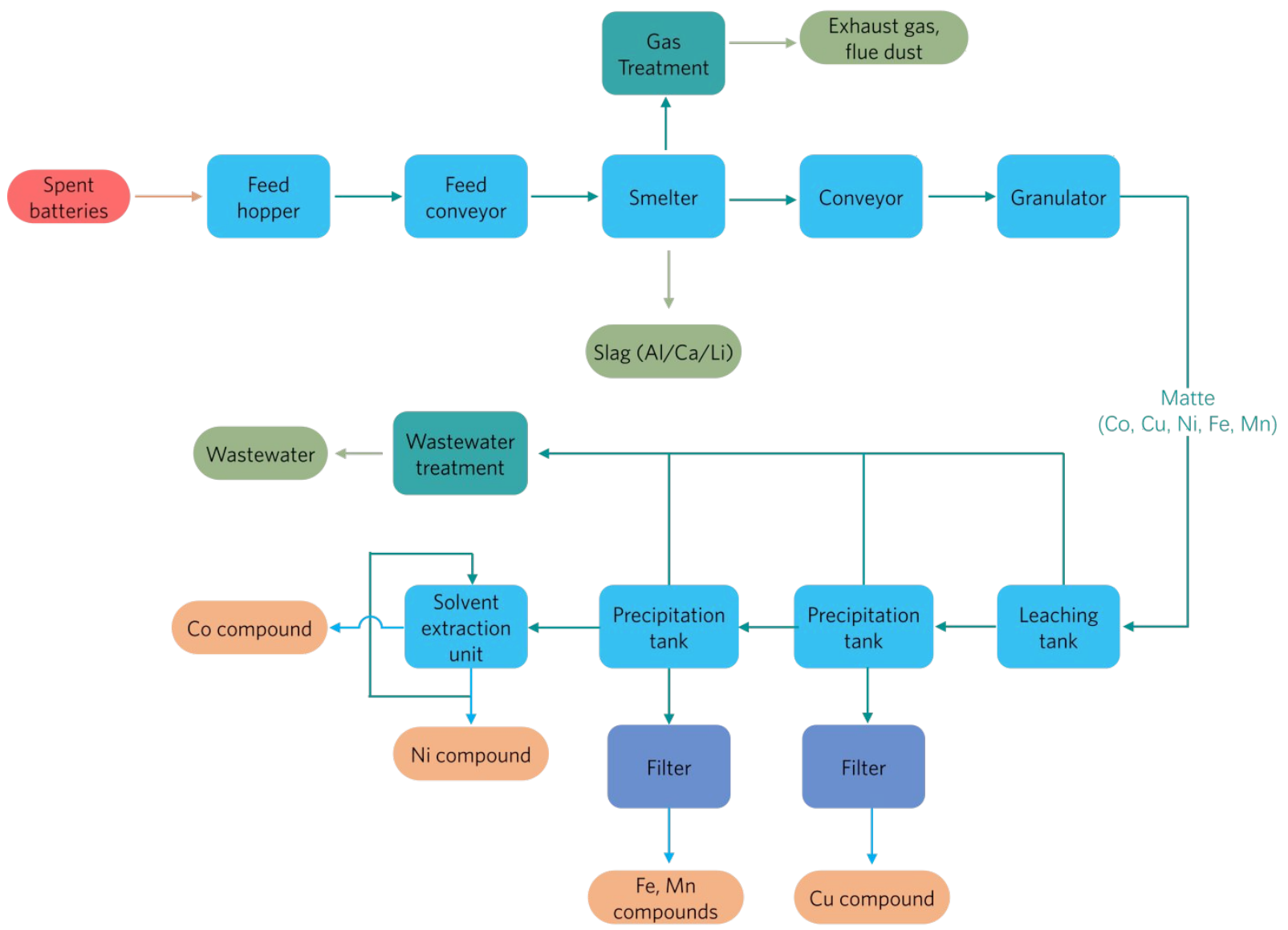

Figure S13. Process diagram of a generic pyrometallurgical recycling process. 


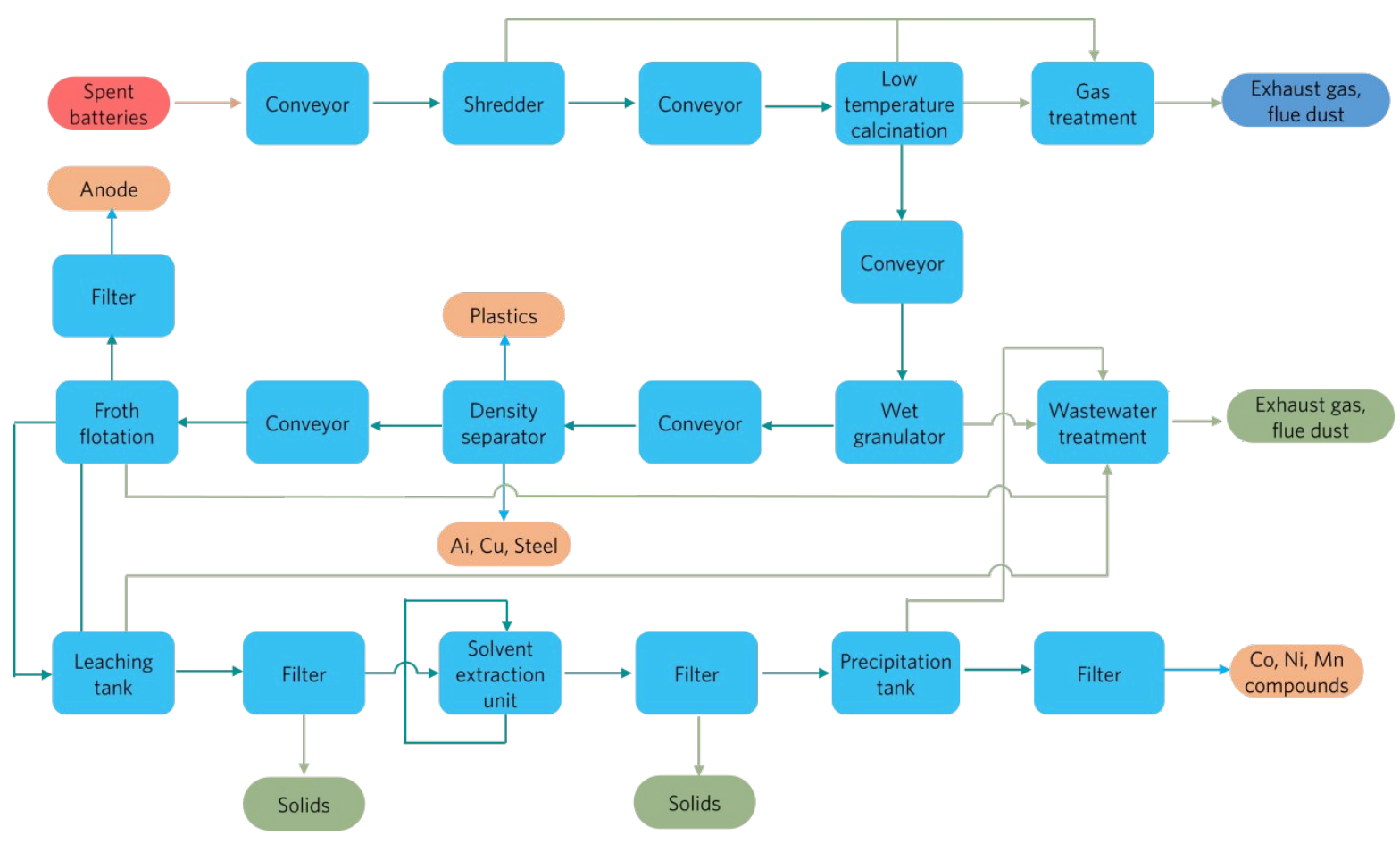

Figure S14. Process diagram of a generic hydrometallurgical recycling process. 


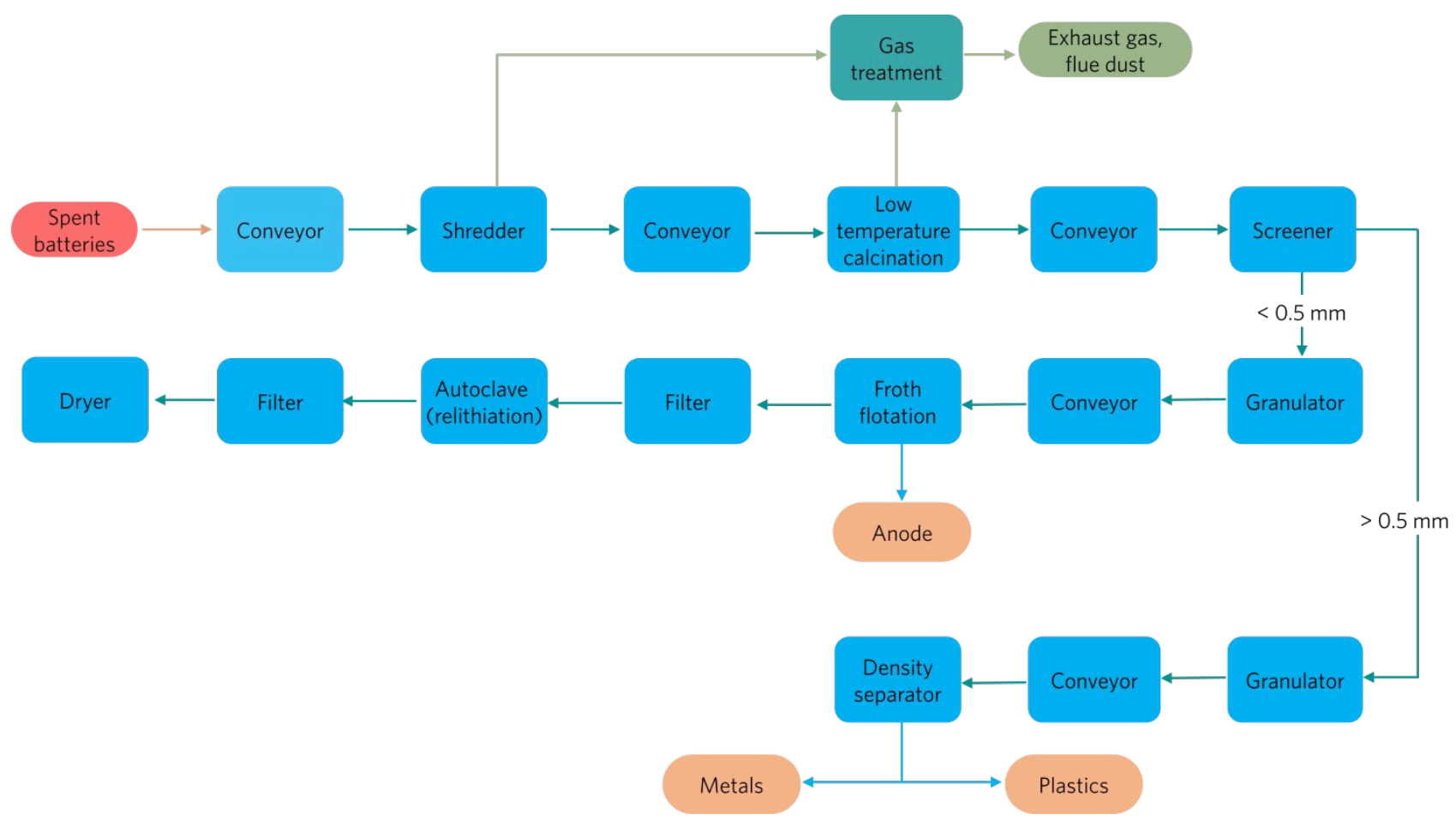

Figure S15. Process diagram of a generic direct recycling process.

\section{Evaluation of energy consumption and greenhouse gas emissions (GHGs)}

Materials input. The materials requirements for the three recycling technologies are summarized in Table S5. The materials requirements for the generic pyrometallurgical and hydrometallurgical processes are obtained from EverBatt, and are reproduced here for the readers' understanding. The materials requirements for the direct recycling process are obtained based on our lab process. Life cycle analysis accounts for the environmental impacts of all the materials consumed in the process(es) by capturing the environmental impacts associated with their upstream production.

Energy input. To calculate the life-cycle environmental impacts attributable to all types of energy consumed in the process(es), life cycle analysis considers the environmental impacts associated with upstream fuel production and electricity generation, as well as those associated with on-site fuel combustion (e.g., diesel/natural gas combustion).

Process emissions. In the life cycle analysis, we also accounted for environmental impacts associated with process emissions that are not due to fuel combustion. For the three recycling processes, process 
emissions include those from material combustion and thermal decomposition. The former arises from burning off materials during the recycling processes, including graphite, carbon black, electrolyte, plastics, and the binder material in the pyrometallurgical process, and electrolyte and the binder material in the hydrometallurgical and direct recycling processes. As the pyrometallurgical process involves burning various battery constituents, it leads to much higher process emissions than those from the other two recycling methods. Total energy use is the cumulative energy use pertaining to the process, including fossil energy use and renewable energy use. Fossil energy use can be further broken down to that of coal, natural gas, and petroleum. GHG emissions are calculated based on 100-year global warming potentials from the fifth assessment report of the Intergovernmental Panel on Climate Change. $^{2}$

Table S5. Materials requirements $(\mathrm{kg})$ to recycle $1 \mathrm{~kg}$ of spent batteries through different recycling technologies.

\begin{tabular}{ccc}
\hline Pyrometallurgy & Hydrometallurgy & Direct recycling \\
\hline Hydrochloric acid & Ammonium hydroxide & Lithium hydroxide \\
Hydrogen peroxide & Hydrochloric acid & \\
Limestone & Hydrogen peroxide & \\
Sand & Sodium hydroxide & \\
& Sulfuric acid & \\
& Soda ash & \\
\hline
\end{tabular}

\section{Evaluation of potential revenue}

The revenue calculation was based on the sales of recycled materials. The prices are obtained from EverBatt and listed in Table S6. The recycled yield of components is assumed to be $90 \%$. " " means the material cannot be accessible in the specific recycling. The weight percentages of $\mathrm{Cu}, \mathrm{Al}$, graphite and NCM111 in a cell are $15.7 \%, 8.2 \%, 19.4 \%$ and $34.7 \%$, respectively. 
Table S6. Value of recycled materials $(\$ / \mathrm{kg})$.

\begin{tabular}{cccc}
\hline & Pyrometallurgy & Hydrometallurgy & Direct recycling \\
\hline Copper & 6.6 & 6.6 & 6.6 \\
Aluminum & $\sim$ & 1.3 & 1.3 \\
Graphite & $\sim$ & 0.28 & 0.28 \\
$\mathrm{Mn}^{2+}$ in product & $\sim$ & $\sim$ & 7.5 \\
$\mathrm{Ni}^{2+}$ in product & 11.3 & 11.3 & $\sim$ \\
$\mathrm{Co}^{2+}$ in product & 51.3 & 51.3 & $\sim$ \\
$\mathrm{Cathode} \mathrm{product}$ & & & 18.72 \\
\hline
\end{tabular}

\section{References}

1. Dai, Q., Gaines, L., Spangenberger, J., Kelly, J. C., Ahmed, S., Wang, M. (2019), Everbatt: A closed-loop battery recycling cost and environmental impacts model. www.Anl.Gov/egs/everbatt. 2. Pachauri, R. K. \& Meyer, L. (2014) Climate Change 2014: Synthesis Report. 1-151 